\author{
POLICY AND ECONOMY IN \\ EMMANUEL MOUNIER'S PERSONALISM
}

\title{
Paolo Cugini*
}

\begin{abstract}
RESUMO
O presente artigo tem como objetivo apresentar a reflexão política e econômica elaborada pelo filósofo francês Emmanuel Mounier e confluída na corrente filosófica apelidada de personalismo. A cidade futura poderá ser realizada somente através de pequenas comunidades, feitas de pessoas responsáveis e maduras, que vivem ativamente a inserção na comunidade, fugindo, dessa forma, do anonimato que marca a vida nas grandes aglomerações. A análise mounieriana da política é intrinsicamente ligada à perspectiva econômica do personalismo, que tem como ponto de partida a crítica do sistema capitalista e do homem burguês. A economia capitalista mortifica a pessoa e, por isso, necessita formalizar uma economia do rosto novo, um rosto personalista. A passagem de uma economia do dinheiro para uma economia da pessoa exige uma firme ruptura. É em defesa dos valores da pessoa que Mounier conduz uma batalha contra a ética do capitalismo, para substituí-la por uma ética do personalismo. Mounier esboça um modelo econômico na perspectiva da pessoa, cuja socialização substitui toda forma de estatização, desenvolvendo a vida sindical para uma conquista da dignidade da pessoa de cada trabalhador.
\end{abstract}

Palavras-chave: Pessoa. Economia. Política. Personalismo. Comunidade.

\begin{abstract}
This article aims to present the political and economic reflection elaborated by the French philosopher Emmanuel Mounier and merged in the philosophical current nicknamed personalism. The future city can only be realized through small communities made of responsible and mature people, who actively live their insertion in the community, thus escaping the anonymity that marks life in large agglomerations. The Mounierian analysis of politics is intrinsically linked to the economic perspective of personalism, which has as its starting point the critique of the capitalist system and bourgeois man. The capitalist economy mortifies the person and therefore needs to formalize an economy of the new face, a personalistic face. The shift from a money economy to a person economy requires a firm break. It is in defence of the values of the person that Mounier wages a battle against the ethic of capitalism to replace it with an ethic of personalism. Mounier outlines an economic model from the perspective of the person, where socialization replaces every form of nationalization, developing union life to achieve the dignity of the individual of each worker.
\end{abstract}

Keywords: Person. Economy. Politics. Personalism. Community.

\footnotetext{
* Doutor em Teologia (Facoltà Teologica dell'Emilia Romagna - Bologna, Itália). Foi professor de Filosofia na Faculdade Católica de Feira de Santana, Bahia - Brasil (2004 a 2013). Diretor da série Cammini della Diversità, Edizioni San Lorenzo (Reggio Emilia - Itália). Colaborador da revista: Adista (Itália). Itália. ORCID: 0000-0003-1251-8344. E-mail: regironspi@gmail.com.
} 


\section{INTRODUÇÃO}

Nos dias de hoje não é fácil encontrar uma reflexão filosófica capaz de acompanhar o andamento político e econômico de um país, mantendo no foco do discurso a dignidade da pessoa humana, mais que os interesses pessoais. O personalismo comunitário, elaborado pelo filósofo francês Emmanuel Mounier (1905-1950) nas páginas da revista Esprit, ${ }^{1}$ por ele mesmo fundada em 1932, oferece esta possibilidade. O Personalismo é uma filosofia elaborada na época da grande crise econômica de 1929, que assolou e abalou a economia do mundo Ocidental. Junto com alguns amigos, Mounier deixou a carreira universitária para se dedicar totalmente a um projeto cultural que tinha como objetivo ajudar na reconstrução do tecido social e moral da sociedade, apontando como ponto de partida a dimensão espiritual da pessoa humana. Não é por acaso que Mounier pediu ajuda para a elaboração deste projeto ao filósofo francês Jacques Maritain (18882-1973), que nos anos 20 do século passado publicou uma obra, considerada inspiradora por esta nova geração de pensadores, com o título Primado do Espiritual (Primauté du spirituel) (MARITAIN, 1927). Foi a partir desta intuição fundamental, cuja essência defende que a estrutura material pode ser mudada somente através de um longo trabalho espiritual que afete toda a humanidade, que Mounier decidiu se dedicar totalmente ao projeto cultural da revista Esprit. ${ }^{2}$ Muito importante no trabalho desenvolvido por Mounier foi a ligação entre a revista e os grupos chamados Les Amis d'Esprit espalhados em todo território francês, mas também na Bélgica e na Suíça. Nesses grupos, os componentes analisavam e discutiam os editoriais da revista e os artigos mais importantes que davam o tema do número do mês. Foi dessa maneira que, lentamente, Esprit formou uma nova geração de intelectuais que muito contribuíram na reconstrução moral da França. Nas páginas seguintes tentaremos acompanhar o pensamento mounieriano sobre os temas da política e da economia na perspectiva personalista, tentando mostrar, como for possível, a grande atualidade destas reflexões.

\section{A CRÍTICA DE MOUNIER AO ESTADO BURGUÊS}

O pensamento político de Emmanuel Mounier é marcado por uma crítica radical ao Estado burguês. 3 A maior acusação é que se trata de um sistema doente na raiz, aquela

\footnotetext{
${ }^{1}$ Para a primeira edição de Esprit, ver MOUNIER, 1932 [nota dos editores].

2 Tentei uma reconstrução histórica do nascimento da revista Esprit em: Pensare cristianamente la storia: Emmanuel Mounier e la rivista Esprit (CUGINI, 2018).

3 Famosos são os primeiros números da revista Esprit, para os quais Mounier e seus colaboradores escreveram artigos, em números especiais da revista dedicados a temas sobre o mundo burguês: O dinheiro: miséria dos
} 
doença que chegou do Iluminismo e que está produzindo, dia após dia, o individualismo, que é o verdadeiro responsável pela instauração do direito abstrato e formal, totalmente alheio à vida da sociedade.

A tomada de consciência do Estado burguês está interligada à crítica da sociedade pós-renascimento, que é um tema fundamental na obra de Mounier. A insistência é sobre a ambiguidade de uma estrutura jurídica, que na aparência é fundada na igualização, enquanto, na realidade, é guiada por interesses pessoais. A democracia liberal burguesa se coloca, portanto, contra a pessoa e é a manifestação do anonimato da sociedade burguesa. Escreve Mounier: "É contra esta democracia que nós somos democratas se, como a maioria dos seus fundadores, entendemos a democracia como o regime principal da responsabilidade pessoal” (MOUNIER, 1984, p. 112). É através desta orientação personalista profunda que se torna democrático um regime, independentemente das formas concretas que possa assumir ao longo da história.

Na época de Mounier, já fazia tempo que a democracia havia parado de ser fiel à própria inspiração originaria. Por isso os fascismos estão se afirmando com força, pois eles representam a manifestação decadente da democracia ocidental. Esta democracia formal e de fachada precisa ser substituída por uma democracia:

Nem tanto parlamentar e de quantidade, mas funcional e orgânica [...] Chamamos de democracia aquele regime que se apoia sobre a responsabilidade e a organização funcional de todas as pessoas que constituem a comunidade social. Somente neste caso estamos do lado da democracia (MOUNIER, 1984, p. 123).

Esta democracia nunca foi realizada no passado, e nunca poderá ser realizada se não houver uma mudança radical de perspectiva. A verdadeira democracia, afirma Mounier, não pode ser confundida com a democracia liberal e parlamentar, mas constitui um futuro que deve ser realizado, e não um dado adquirido para defender (MOUNIER, 2003, p. 76).

Em Carta aberta sobre a democracia, de 14 de fevereiro de 1934, publicada na revista Esprit, 4 afirma que "a ideologia contra a qual nós lutamos é a ideologia de 1889. Trata-se, de fato, de uma ideologia individualista e abstrata, que sufoca a liberdade e é promotora do reino do dinheiro" (CUGINI, 2018, p. 98) que, ao mesmo tempo, sufoca a vida pessoal. Por isso é preciso uma nova democracia, e é neste mesmo sentido que a Revolução personalista está impulsionando a sociedade.

pobres, miséria dos ricos (outubro 1933) (MOUNIER et al., 1933); Carta sobre o mundo burguês (março 1933) (MARITAIN, 1933); A máquina contra o proletário (julho 1933) (MARC, 1933), A crise da democracia e a reforma do Estado (junho 1934 a fevereiro 1935) (DAMI, 1934-1935).

4 Publicado em Esprit v. 32, Révolution personnaliste et communautaire (MOUNIER, 1935). 
Mounier afirma que a ação política, assim como em sua época era entendida, está viciada no seu mais profundo jeito de ser. Parece que o único sentido da política seja a busca do poder, a conservação das instituições, perdendo sempre mais o contato com as pessoas. Esse apego desmesurado às instituições não é nada mais que a herança do velho mito otimista, tipicamente burguês. Conforme Mounier: "Do nosso lado nós não acreditamos no milagre das instituições. Na futura sociedade personalista o elemento institucional será limitado o mais possível para proteger a pessoa.” (MOUNIER, 1984, p. 317-319).

O pior sintoma da doença social da Europa entre as duas guerras mundiais não é tanto a crise das instituições, mas o progressivo desfecho da política. Na perspectiva personalista apresentada por Mounier nas páginas da revista Esprit, é preciso estar na política sem se tornar políticos (MOIX, 1968). A responsabilidade da crise da política é dos partidos. De fato, enquanto a tarefa de um partido político seria aquela de formar a classe dirigente, na realidade estão transferindo para o Estado a ideologia deles, para influenciar o povo e, assim, impor as próprias ideias. Dessa maneira, os partidos, ao invés de realizarem um serviço para a sociedade, tornam-se cúmplices de toda forma de manipulação ideológica. É por esta razão que, para Mounier, a revolução não pode ser feita e nem articulada pelos partidos, pois na atualidade, são parte integrante do sistema que se quer derrubar. 5

Nas páginas de Revolução Personalista e Comunitária que, na realidade, trata-se de uma coletânea de artigos que o mesmo Mounier publicou na revista Esprit, o jovem filósofo francês, de forma coerente, continua a crítica ao sistema político francês já esboçada na época da elaboração doutrinal de Esprit (CUGINI, 2018, p. 81-83; WINOCK, 1975, p. 132158). Foi exatamente sobre este ponto crítico, ou seja, a tarefa dos partidos políticos, que Mounier provocou a rachadura entre a revista Esprit e a Troisiéme Force, um partido de esquerda, que no começo caminhou junto com os colaboradores de Esprit.

Na ótica de Mounier, era necessário substituir a velha ideia liberal por uma nova concepção do Estado e do poder, para passar de uma democracia individualista para uma democracia personalista. "Toda forma de autêntica democracia coloca a preocupação da pessoa humana no centro do debate político e de qualquer instituição pública” (MOUNIER, 1964, p. 23).

\footnotetext{
5 É conhecida a desconfiança de Mounier no confronto dos partidos políticos. Foi essa desconfiança que o levou a romper com a Troisième Force, partido nascido com a intenção de ser o órgão político partidário da revista Esprit. Sobre esse período histórico da vida de Mounier, ver WINOCK, 1975.
} 


\section{UMA NOVA CONCEPÇÃO DO PODER: RUMO AO ESTADO PLURALISTA}

Antes de reformar o Estado, é preciso refletir sobre o sentido e a essência do poder. É isso que Mounier quer fazer, polemizando com a concepção anárquica do Estado, desenvolvendo aquela que ele mesmo define como a doutrina personalista da autoridade:

No mundo verdadeiro, onde o espírito é de forma contundente interligado à carne, não existe autoridade que não se traduza, para homens solicitados de qualquer forma por tendência discordantes, numa forma de constrição; não existe poder que possa legitimarse, e até durar, sem uma autoridade que ele exerce, mas não cria (MOUNIER, 2003, p. 37).

Mounier elabora uma distinção entre autoridade e poder. À diferença do poder, a autoridade é exclusivamente pessoal e, portanto, o poder pode ser justificado porque aceita se colocar à serviço da pessoa que seja consciente dos próprios limites:

O poder tem como finalidade o bem comum e a pessoa, que não é a soma dos interesses individuais. [...] Este bem comum não pode pisotear uma só pessoa, não pode recusar espaço para um só ato de autêntica liberdade espiritual. Sobretudo o bem comum não pode substituir-se às pessoas nas decisões das quais depende o destino delas mesmas (MOUNIER, 2003, p. 45).

O Estado liberal não consegue manter o equilíbrio entre proteção à vida pessoal e às exigências da vida social. Trata-se, então, de fundamentar uma nova relação entre o homem e a sociedade; um relacionamento que consiga favorecer a superação de toda forma de individualismo e a expansão da vida pessoal, com a consequente criação de estruturas personalistas e comunitárias. O Estado é considerado, para Mounier, exclusivo ao serviço da pessoa, e neste serviço encontra um limite absoluto de valor:

A sociedade, quer dizer, o regime legal, jurídico, social e econômico, não tem a missão de subordinar as pessoas, nem de se meter no desenvolvimento da vocação específica de cada uma, mas de garantir um espaço de isolamento, de proteção, de serenidade, que permitirá a cada um reconhecer, na total liberdade de desenvolvimento, a própria vocação. Todo homem deve ter a possibilidade de se libertar de toda forma de estrutura, pois até as melhores instituições podem produzir os piores resultados se os homens que as dirigem não fazem desta libertação o princípio fundamental da vida (MOUNIER, 1984, p. 78-79).

É no Manifeste au servisse du personnalisme (MOUNIER, 1975) que Mounier visa aprofundar o relacionamento entre pessoa e Estado. Não é, de fato, a pessoa que deve ser para o Estado, mas é o Estado que deve ser pela pessoa. O Estado não é uma comunidade espiritual, uma pessoa coletiva, no sentido autêntico da palavra, mas é um instrumento a 
serviço da sociedade e das pessoas. O Estado é percebido como árbitro dos conflitos entre as pessoas e os grupos sociais, mas sobretudo como servidor das pessoas, como autoridade que se coloca a serviço da vida das pessoas (MOUNIER, 1975). Mounier insiste sobretudo nos limites que o Estado deve ter, pois não pode haver um Estado com poderes absolutos. "O Estado personalista não é uma igreja, não é também um grupo filosófico neutro e indiferente, como é, pelo menos na teoria, o Estado liberal. O Estado personalista, não é neutro, está ao lado da pessoa" (MOUNIER, 1975, p. 121).

O Estado se coloca no plano do poder, da autoridade, não no nível da potência, ou seja, da força: o personalismo não ameaça a autoridade, mas a consolida, no momento em que vai se opondo a todo sistema de força e violência. Trata-se de símplices indicações, que o movimento personalista deixou ao estado de esboço, devido também à escassa participação de juristas e de políticos na elaboração do programa do movimento personalista. A doutrina de Mounier, do Estado, termina numa reivindicação do valor da pessoa, e das comunidades nas quais se expressa, no confronto com o Estado. O pluralismo social encontra uma específica colocação no quadro geral das reações ao estatismo político e jurídico. A passagem do Estado autoritário para um Estado personalista, que prevalecia na Europa entre as duas guerras, era um dos pontos fundamentais do programa elaborado nos primeiros números da revista Esprit, segundo a qual, a possibilidade de um Estado pluralista era considerada como uma das reivindicações fundamentais do novo movimento (CAMPANINI, 1968).

Na perspectiva do personalismo de Mounier, a exigência de um limite constitucional dos poderes do Estado deve ser garantida através do equilíbrio entre poder central e as administrações locais. Somente assim é possível tutelar os direitos dos cidadãos, junto com a independência do poder judiciário. "Se a pessoa pode ser submetida, deve ser feito conservando o mais possível a soberania do sujeito reduzindo ao mínimo possível a inevitável alienação, que é produzida no relacionamento com o governo" (MOUNIER, 1984, p. 128). Esta alienação pode ser em parte superada, através da participação na gestão do poder junto com a instauração de uma autêntica democracia. Essa participação não pode ser exercida através dos partidos, mas através de novas estruturas de formação e de ação política, adaptadas à nova situação social. Por este caminho, a pessoa pode influir na gestão da vida pública e modificar a estrutura do Estado, até ele se tornar Estado pluralista, entendido como: "Estado articulado ao serviço de uma sociedade pluralista" (MOUNIER, 2014, p. 154).

Essa articulação do Estado se expressa através da presença de muitos corpos sociais, 
capazes de exprimir uma vontade própria e de influenciar a gestão da máquina pública. Além disso, tem poderes locais e regionais que devem ser desenvolvidos através de um aliviamento do Estado (DANESE, 2012). Um aspecto fundamental deste pluralismo é o pluralismo cultural. Se a tarefa importante da sociedade é ajudar as pessoas a se realizarem, a função da educação neste processo é de suma importância. A educação tem como tarefa despertar o ser das pessoas, para que aprendam a viver com dignidade. Por isso, Mounier sempre foi contrário a qualquer forma de totalitarismo escolar, propondo com vigor uma sociedade pluralista. "A tarefa educativa não pode ser prioridade do Estado, pois é a comunidade natural, entre ela a família, apesar de que ela, no processo educativo dos filhos, também deve aprender a respeitar, em todo momento evolutivo, a personalidade da criança” (MOUNIER, 1975, p. 89).

A família tem uma tarefa de suma importância na dialética entre Estado e pessoa. De fato, enquanto Mounier marca o caráter natural da família, ao mesmo tempo aponta a sua anterioridade no confronto do Estado. Por essa razão, o Estado deve sempre ficar atento a não atrapalhar a tarefa da família na educação das crianças. É por isso que, nas páginas da revista Esprit dedicadas ao tema educação, Mounier reiteradamente, enquanto alerta o Estado a não prevaricar o espaço primário das famílias na educação dos filhos, ao mesmo tempo favorece a formação das comunidades locais. É nesse nível comunitário que devem ser ativadas as dinâmicas de colaboração estrita entre as estruturas de poder e as pessoas. "O Estado não é uma pessoa coletiva, mas um árbitro entre pessoas coletivas e individuais" (MOUNIER, 2018, p. 37). Por essa razão, na concepção personalista elaborada nas páginas da revista Esprit, o Estado não deveria possuir algum bem e, se tivesse, deveria restituir às cooperativas coletivas da comunidade, para limitar a sua intervenção nos serviços coletivos.

Por que Mounier insiste tanto assim nesse aspecto da economia do Estado, tentando a toda hora limitar o máximo possível a sua intervenção? A pergunta é necessária pois, apesar de tudo, a função do Estado é fundamental para garantir a vida pessoal de todo cidadão. Potenciar a economia de um Estado significa, para Mounier, abrir o espaço de toda forma de corrupção. Por isso, “o Estado deve permanecer essencialmente um legislador, um árbitro e um protetor das pessoas contra as comunidades intermédias, como também deve permanecer um protetor das comunidades orgânicas contra a anarquia individual” (MOUNIER, 2018, p. 179).

É nessa perspectiva que se torna necessário passar de uma democracia formal para uma democracia orgânica. Além disso, outra forma de descentralização é aquela dos corpos sociais e das associações econômicas. Para evitar que o Estado se torne totalitário, é 
necessário prever estruturas que sejam descentralizadas para que cheguem até as pessoas. "Só assim será possível desarticular o poder numa série de comunidades, algumas sendo colocadas em planos sobrepostos, outras interdependentes umas às outras, mesmo conservando uma certa autonomia" (MOUNIER, 1984, p. 232).

A proposta da revolução personalista e comunitária elaborada nas páginas da revista Esprit nos primeiros anos da sua atividade editorial - 1932-1935 - não propõe construir uma nova forma de Estado, nem substituir o Estado como mera estrutura jurídica, mas uma comunidade de pessoas interligadas entre elas por uma série de vínculos e sustentadas por uma mesma ordem jurídica, porém caracterizada por uma dinâmica dialética interna. A sociedade que Mounier sonha e planeja em seus artigos publicados na revista Esprit é feita de grandes e pequenas comunidades, que se encontram nas escolas e nas fábricas, na cidade e no campo. É nessas comunidades que as pessoas podem encontrar a si mesmas e conseguir realizar a própria e específica vocação.

A criação de pequenas comunidades é considerada uma condição essencial para tentar pôr um freio ao processo de despersonalização das estruturas, que caracteriza a sociedade moderna. Nesse sentido, é possível afirmar que "a civilização personalista é o princípio de uma civilização comunitária, porque as pessoas alcançam a sociedade através das comunidades de pessoas, que é um novo tipo de estrutura social” (MOUNIER, 1975, p.79).

Nesse processo, que tende sempre mais na direção da personalização da sociedade, é possível destacar alguns movimentos fundamentais. Em primeiro lugar, encontramos a Société en nous autres, que é o vínculo da amizade e do amor. Depois disso, encontramos as chamadas sociedades totais (a família, a cidade), fundadas essencialmente sobre valores biológicos e de proximidade. Enfim, as sociedades de razão são caracterizadas por um forte abstracionismo, nas quais encontramos as sociedades jurídicas contratuais e, entre elas, o Estado. Preocupadas somente com os aspectos jurídicos dos relacionamentos com os homens, e carente de uma ligação com as pessoas, estas sociedades "levam nessa forma estritamente jurídica, um germe de opressão" (MOUNIER, 1975, p. 80).

É bom lembrar que as várias sociedades que estruturam um corpo social permanecem parciais. A verdadeira comunidade é a personalista, a única a ser pessoa, de pessoas. Essa sociedade personalista é alicerçada no amor, e não sobre a constrição. Mounier é plenamente consciente que a sociedade real está bem longe da comunidade perfeita, pois nela encontramos conflitos, interesses particulares. É preciso fazer de tudo para reduzir ao mínimo as tensões, apesar da consciência de que sempre haverá alguma tensão. Este é um 
elemento específico da democracia, ou seja, a capacidade de conviver com as tensões, superando a tentação típica dos regimes totalitários de aniquilar o inimigo, aquele que pensa de forma diferente. É por isso que o personalismo não pode se limitar a organizar uma ação sobre as pessoas, mas deve se articular para agir também sobre as instituições, conforme uma dúplice direção: evitar qualquer forma de opressão sobre as pessoas e protegê-las contra toda tirania. "Somente assim, é possível ajudar as pessoas a se realizarem" (MOUNIER, 1975, p. 81).

A cidade futura poderá ser realizada somente através de pequenas comunidades feitas de pessoas responsáveis e maduras, que vivam ativamente a inserção na comunidade, fugindo, desta forma, do anonimato que marca a vida nas grandes aglomerações:

Toda vez que na história se decompõem as comunidades existentes, comunidades fragmentárias, perdidas como pequenas ilhas, vão se constituindo, através do processo de decomposição, ao redor do núcleo das pessoas que permaneceram. Uma das tarefas essenciais da revolução orgânica é de estimular, revelar, ajudar e unir entre elas estas comunidades (MOUNIER, 1984, p. 146).

Não é fácil a tarefa de modificar a mesma estrutura da sociedade através da expansão e da articulação destas pequenas comunidades. ${ }^{6} \mathrm{Na}$ elaboração personalista, que nos anos 1930 Mounier vinha desenvolvendo, era a única perspectiva possível. Ele tinha a certeza de que a revolução tão almejada, não apenas do grupo Esprit e dos partidos de esquerda, mas também de muitos círculos culturais nascidos naquela época, era possível somente pelo caminho traçado nas páginas de Esprit. Dirá Mounier numa das últimas obras da sua breve vida: "Foi por esta razão que desde o começo sempre associamos de forma indissolúvel os termos personalista e comunitário.” (MOUNIER, 1948, p. 69). A revolução pode ser personalista somente enquanto é comunitária, e vice-versa.

\section{LINHAS DE UMA ECONOMIA PERSONALISTA}

Entre pessoa e ambiente existe uma recíproca correlação no personalismo mounieriano. A sociedade incide bastante sobre a formação da personalidade. Podemos, então, afirmar que "as estruturas sociais mandam em parte nas nossas relações individuais e condicionam o mesmo afirmar-se da personalidade” (MOUNIER, 1990, p. 477). Por isso, uma filosofia personalista deve interessar-se das estruturas sociais, mesmo porque elas

\footnotetext{
${ }^{6}$ Esta tentativa foi experimentada por Mounier através a constituição dos pequenos grupos chamados de amigos de Esprit (Les Amis d'Esprit) que, no período entre as duas guerras mundiais, eram espalhados em todo o território francês (cf. WINOCK, 1975).
} 
condicionam de uma maneira contundente a pessoa. Trata-se de uma tese espiritualista e falsa aquela que sustenta que a estrutura social não tem a ver com o crescimento e o desenvolvimento da pessoa. Uma filosofia personalista não pode deixar de lado as estruturas sociais, pois elas condicionam, e muito, a pessoa. Entre esses condicionamentos, os mais influentes são os condicionamentos econômicos. Apesar de recusar a filosofia materialista do marxismo clássico, Mounier reconhece com Marx a conexão entre estruturas econômicas e valores espirituais. Somente libertando o homem dos condicionamentos econômicos, é possível realizar um caminho de autenticidade da pessoa.

É nessa altura que se coloca a crítica à economia capitalista, que mortifica a pessoa e, por isso, necessita formalizar uma economia do rosto novo, um rosto personalista. A passagem de uma economia do dinheiro, para uma economia da pessoa, exige uma firme ruptura. De fato, o capitalismo não pode ser melhorado, mas destruído, pois é o mesmo capitalismo que: "tornando-se tirânico produz com os seus métodos o tiranicida que um dia virá para reivindicar a herança da ordem” (MOUNIER, 1975, p. 37). A condenação do capitalismo é ao mesmo tempo ética e econômica. Ética porque o capitalismo oprime as pessoas. Econômica porque não consegue elaborar um projeto capaz de beneficiar todas as pessoas. Numa passagem, que reflete muito os ensinamentos do seu mestre Péguy, Emmanuel Mounier esclarece a sua crítica ao capitalismo:

O dinheiro esvazia o homem e interioriza o egoísmo. Esvazia a comunidade dos relacionamentos humanos para preenchê-la com a máquina impessoal. O dinheiro penetra no mesmo coração da vida privada colocando nele, fabricados pela própria matéria, novos modelos humanos. (MOUNIER, 1984, p. 271).

Assim, no reino do dinheiro perde-se o sentido do outro, e a riqueza produz fenômenos de despersonalização que se espalham em todas as classes sociais, difundindo em toda a sociedade uma mentalidade de pequena burguesia. A condenação do capitalismo nas páginas de Mounier é radical e sem atenuantes: “De qualquer lado se vê o universo do capitalismo moderno. Deixando de lado as soluções técnicas esporádicas, encontramos somente falhas e corrupção.” (MOUNIER, 1984, p. 97).

A denúncia mounieriana ao capitalismo nasce de uma contestação da sua base metafísica, ou seja, do otimismo liberal, fundamentado sobre a presunção de que a economia, deixada a si mesma, possa dar vida a uma sociedade digna do homem. Na realidade, a economia capitalista sufoca a pessoa. Assistimos, de fato, a uma opressão íntima da mesma vida pessoal, com o sufocamento de toda espontaneidade, de cada valor e da generosidade humana em detrimento do valor do dinheiro. Torna-se impossível, por isso, 
pela maioria dos oprimidos, ter acesso a uma vida humana que estimule também a vida interior. Por essa razão, Mounier leva a sua crítica contra o capitalismo no plano religioso. O burguês representa uma espécie de anticristo. O burguês é o homem que perdeu o sentido da pessoa e do mistério; ele sabe se relacionar com as coisas. Mas muito menos com as pessoas. "Sendo que o burguês ama somente o dinheiro, não pode amar a Deus e é por isso que o ateísmo é algo que pertence ao mundo burguês.” (MOUNIER, 1984, p. 374).

A concepção burguesa da propriedade parece, ao entender de Mounier, essencialmente materialista e, por isso, contra o cristianismo. O capitalismo não consegue enxergar o mundo na sua relação com o homem, na única perspectiva em que as coisas têm sentido. Isso é devido a uma forma radical de materialismo intrínseco ao mesmo capitalismo que, paradoxalmente, o aproxima ao marxismo. "O capitalismo, como o comunismo, é a heresia que atribui ao homem o eminente domínio de Deus.” (MOUNIER, 2018, p. 34).

O caminho para a solução dos problemas espirituais passa através a solução dos problemas econômicos. Para defender os valores da pessoa, Mounier conduz uma batalha contra a ética do capitalismo, para substituí-la com uma ética do personalismo. A visão extremamente negativa de Mounier sobre a classe burguesa, culpada de ter produzido uma economia que escraviza a pessoa, o leva a excluir qualquer forma de ligação com a burguesia, auspicando o advento de uma nova economia - não viciada nas distorções da economia capitalista, toda focada no produto, esquecendo constantemente a pessoa - , mas uma nova economia personalista, baseada na pessoa, garantindo a cada uma o mínimo vital, oferecendo a cada uma a segurança do trabalho e da existência. Quando a economia coloca no centro dos próprios interesses a pessoa, a mesma sociedade é beneficiada, pois as pessoas aprendem a viver de forma harmoniosa numa comunidade de vida e de destino.

A nova economia de inspiração personalista é uma economia pluralista, que representa a síntese entre liberalismo e coletivismo. Mounier é orientando a pensar uma economia com dois setores distintos: um primeiro, que articula os bens pela produção de base; um outro, mais livre, que garante um mínimo de subsistência. Trata-se de um modelo econômico substancialmente socialista, caracterizada por uma forma de gestão comunitária do poder econômico, que visa à abolição da condição do proletariado. Em outras palavras, Mounier esboça um modelo econômico na perspectiva da pessoa, no qual a socialização substitui toda forma de estatização, desenvolvendo a vida sindical para uma conquista da dignidade da pessoa de cada trabalhador. Quando Mounier fala de "opção para o socialismo" (MOUNIER, 1975, p. 311) é isso que quer dizer, ou seja, um modelo econômico que constantemente tenha ao centro de qualquer planejamento a pessoa humana, tendo em vista 
a construção de um mundo mais humano. Como já foi analisado no âmbito da crítica personalista (CAMPANINI, 2005), nessa altura do discurso, economia socialista e economia personalista coincidem.

Para a realização da passagem entre economia capitalista e economia personalista, Mounier não pensa em qualquer forma de gradualidade reformista, pois torna-se necessário um salto qualitativo e não uma mera ação de maquiagem oportunista. Além disso, essa transformação, longe de ser obra de um grupo de ideólogos, deve ser garantida pelo Estado. É ele, de fato, que deve criar uma nova legislação econômica, capaz de aniquilar por dentro o sistema econômico capitalista. Uma sociedade que não seja capitalista nem coletivista deve fundamentar a própria economia sobre alguns valores básicos: a institucionalização da liberdade; a prioridade do trabalho sobre o capital, a prioridade do serviço social sobre o proveito. Os meios que Mounier sugere para realização desses objetivos são a eliminação da renda, a reorganização da Bolsa (que deve se tornar meio de simples regulamentação do mercado), o controle do redito. Esses instrumentos econômicos devem produzir como efeito o fim do reino da fecundidade anônima do dinheiro. "É preciso reconduzir o capital, assim purificado nas suas raízes, a coincidir com o trabalho, com a responsabilidade e as necessidades." (MOUNIER, 1984, p. 277).

Além disso, o novo regime econômico deve ter como proposta a participação da propriedade, da gestão das indústrias e toda a economia, no geral, de todos os trabalhadores organizados, junto com os consumidores para, assim, dar vida a um sistema econômico caracterizado por uma propriedade parcialmente coletiva.

Entre os meios apontados para alcançar essa requalificação do capital, são indicadas as estruturas corporativas e associativas. Nessa reestruturação da economia, uma função de primeiro plano é confiada ao progresso técnico. Através da mecanização, aumenta-se a produtividade e diminui-se o peso dos condicionamentos da fadiga. "Teremos um mundo onde desaparecerão a angústia primitiva do mínimo indispensável pela vida, a dificuldade do esforço material e a preocupação pelo amanhã.” (MOUNIER, 1984, p. 409).

Mounier apresenta, nas páginas de Revolução personalista e comunitária, uma proposta segundo a qual os bens materiais poderão ser oferecidos ao homem e à mulher em uma medida nunca conhecida no passado. O filósofo fundador da revista Esprit é bem consciente de que tudo isso não resolverá os problemas das pessoas, sobretudo se a nova perspectiva econômica produz um estilo de vida burguesa. A proposta econômica do personalismo se, de um lado, tende a maximizar a produtividade, a difusão do bem-estar material, garantindo a todos um mínimo vital e a segurança do trabalho, do outro lado 
recusa o bem-estar como ideal e como mito. Então, o caminho pela superação das estruturas capitalistas não se resolve numa ética do bem-estar, mas numa ética da pobreza, numa visão acética e austera da sociedade. "Ai daquela revolução que vence a miséria do pobre e a substitui para todos os homens, com a espantosa miséria do rico.” (MOUNIER, 1984, p. 410).

É preciso servir-se da abundância assegurada para um melhor uso das riquezas da terra, para deixar sempre mais clara a distância do homem dos bens materiais. Para Mounier, a verdadeira riqueza não é uma acumulação de bens sensíveis, mas uma pobreza brilhante. Somente esse tipo de pobreza permite que a vida espiritual não sufoque uma vida confortável. "O ideal de vida pelo qual devemos lutar é um ideal de pobreza vivente ou, se se prefere, de generosidade simples. Dois são, então, os inimigos que precisamos derrotar: a riqueza e a miséria." (MOUNIER, 2018, p. 79).

No Manifesto ao Serviço do Personalismo (MOURNIER, 1975), encontramos as páginas em que Mounier aprofunda e esclarece o sentido do elogio à pobreza, que apresenta uma espécie de saída à proposta burguesa duma riqueza que esvazia o homem. Existe uma pobreza que clareia a alma de toda forma de aventura superficial e a rende livre para continuar serena no caminho da vida.

Uma certa pobreza é o estatuto econômico ideal da pessoa: por pobreza não entendemos um ascetismo exacerbado e uma avareza vergonhosa, mas uma difidência do peso de certos acessórios, um gosto pela simplicidade, um estado de disponibilidade e de leveza que não exclui nem a magnificência, nem a generosidade, nem sequer um uso importante das riquezas, se isso é garantido contra a avareza (MOUNIER, 1975, p. 114).

É claro que, com esse discurso, saímos do plano da economia para entrarmos no plano da ética. Mais uma vez, na argumentação de Mounier, a inspiração ética tem a prevalência sobre aquela da política, inspiração ditada por uma escolha sem dúvida muito pessoal. É um erro pensar que seja possível salvar a pessoa, garantindo a sua possibilidade de escolha livre, sem uma clara e precisa intervenção nas estruturas sociais e coletivas. É um erro também pensar que essa ação coletiva possa substituir a escolha que cada pessoa é chamada a realizar. Um empenho total para a superação do sistema capitalístico se resolve numa sociedade pessoal, através de um regime de pobreza, em nome de um juízo ético que saiba esclarecer as luzes e as sombras do bem-estar econômico.

A tensão revolucionária retoma a sua força espiritual e moral, intimamente religiosa, porque entende que o bem-estar material pode ser apenas a moldura que permite a cada pessoa a própria realização, não num relacionamento anônimo com as coisas, mas no 
relacionamento vivo com homens vivos, e com aquele vivente que para Mounier é a pessoa suprema .

\section{CONSIDERAÇÕES FINAIS}

Sabemos que Mounier elaborou o próprio pensamento político e econômico na perspectiva personalista na época da grande crise econômica que alastrou o mundo nos anos 1930. Por isso, as suas páginas não apenas são interessantes, mas oferecem estímulos também para o debate atual. Uma leitura atenta das páginas de Mounier conduz o leitor a perceber o seu pensamento como uma linha de demarcação entre utopia e profetismo. Se, por um lado, é louvável pensar um Estado que tenha como foco os próprios interesses à dignidade da pessoa humana, do outro lado, conhecendo o caminho da história, sabemos como esta hipótese pode ser bastante mal atendida e, por isso, relegada ao mundo das utopias. É mais profícuo e interessante acompanhar a linha profética do pensamento de Mounier pois encontramos, sem dúvida, muitos pontos de interesse do nosso debate econômico e político atual. O centro do pensamento político de Mounier é a estrita conexão entre a filosofia da pessoa e a filosofia da revolução. É a concepção mounieriana da pessoa que alicerça a filosofia da revolução, feita sobretudo utilizando a categoria do empenho, verdadeiro eixo da filosofia personalista. Trata-se, de fato, de um pensamento militante, que se esforça em compreender a realidade para transformá-la. É por esse caminho que a filosofia se torna revolução, que é ao mesmo tempo espiritual e econômica.

Não será surpresa se encontramos nas páginas centrais da obra $O$ Personalismo (MOUNIER, 2014), uma das últimas de Mounier, a reflexão sobre o dinamismo entre interioridade e exterioridade. É essa a preocupação de Mounier na busca constante do lugar do cristianismo na história, cuja presença sempre oscilou entre a fuga na interioridade e o desejo de influir na sociedade. O encontro entre valores religiosos e valores civis pressupõe, como ponto de partida, o corte claro com as estruturas do passado e, assim, o fim da mesma cristandade rumo ao novo renascimento. No pensamento de Mounier, encontram uma estrita conexão entre o empenho cristão e a exigência revolucionária e, ao mesmo tempo, a tomada de consciência de que a crise da civilização ocidental é inseparável da crise da cristandade. A civilização ocidental está em crise, porque está em crise a cristandade ocidental e vice-versa.

A atitude do cristão é um empenho total numa libertação contínua. Dessa maneira, a concepção cristã condena toda forma de utopia moral e social, mas nem por isso encoraja 
uma civilização doentia. A fundamental opção pela dimensão transcendente feita pelos cristãos não exclui a atenção ao empenho na dimensão temporal. É por isso que Mounier dedica tempo e esforço intelectual para elaborar uma técnica do Estado personalista, pois é preciso se empenhar para construir uma cidade terrena, apesar de ter consciência de que ela nunca será como a cidade celeste. $\mathrm{O}$ cristianismo "recusa reconduzir à tragédia a totalidade da experiência espiritual.” (MOUNIER, 1979, p. 37).

É o princípio da encarnação, ao qual Mounier dedica páginas memoráveis (cf. MOUNIER, 1984), que faz parte da herança cultural do seu mestre Charles Péguy (cf. PÉGUY, 2013; MOUNIER, 1987), que leva os cristãos a se interessarem pela história das estruturas políticas e econômicas. "Nós não precisamos levar o espiritual no temporal, pois ele já se encontra lá. A nossa tarefa é descobri-lo e fazer com que ele viva. O temporal na sua totalidade é o sacramento do reino de Deus" (MOUNIER, 1979, p. 41).

O sentido autêntico do pensamento político de Mounier segue na direção de oferecer, com a revolução personalista e comunitária, uma resposta cristã à crise da civilização. Os tempos mudaram, mas a possibilidade de ver uma classe política capaz de elaborar projetos econômicos, visando à dignidade da pessoa e não o lucro pessoal, permanece um sonho atual. Mounier, com a sua obra, ajudou bastante para que esse sonho se traduzisse em realidade.

\section{REFERÊNCIAS}

CAMPANINI, Giorgio. La rivoluzione Cristiana: il pensiero politico di Emmanuel Mounier. Brescia: Morcelliana, 1968.

CAMPANINI, Giorgio. Incontro con Emmanuel Mounier. Lugano: EUPRESS-FTL, 2005 .

CUGINI, Paolo. Pensare cristianamente la storia: Emmanuel Mounier e la rivista Esprit. Roma: Ilmiolibro, 2018.

DAMI, Aldo. La crise de la démocratie et la réforme de l'état. Esprit, Paris, n. 21; 22; 23$24 ; 25 ; 26 ; 27 ; 29$, juin 1934 à février 1935. 7 articles. Disponível em:

https://esprit.presse.fr/recherche?search=La+crise+de+la+d\%C3\%A9mocratie+et+la+r\% $\mathrm{C}_{3} \%$ A9forme + de $+1+\% \mathrm{C}_{3} \% 8$ tat. Acesso em: 28 out. 2020.

DANESE, Attilio. Il problema antropologico: il personalismo di Emmanuel Mounier. Roma: Ametista, 2012.

MARC, Alexandre. La machine contre le prolétaire. Esprit, Paris, n. 10, juillet 1933. Disponível em: https://esprit.presse.fr/article/marc-alexandre/la-machine-contre-leproletaire-27838. Acesso em: 28 out. 2020. 
MARITAIN, Jacques. Primauté du spirituel. Paris: PLON, 1927.

MARITAIN, Jacques. Lettre sur le monde bourgeois. Esprit, Paris, n. 6, mars 1933. Disponível em: https://esprit.presse.fr/article/maritain-jacques/lettre-sur-le-mondebourgeois-19475. Acesso em: 28 out. 2020.

MOIX, Candide. O pensamento de Emmanuel Mounier. Rio de Janeiro: Paz e Terra, 1968.

MOUNIER, Emmanuel. Refaire la renaissance. Esprit, Paris, n. 1, octobre 1932.

Disponível em: https://esprit.presse.fr/tous-les-numeros/324. Acesso em: 28 out. 2020.

MOUNIER, Emmanuel et al. L'Argent: misère du pauvre, misère du riche. Esprit, numéro spécial, octobre 1933. Disponível em: https://esprit.presse.fr/article/esprit/l-argentmisere-du-pauvre-misere-du-riche-30464. Acesso em: 28 out. 2020.

MOUNIER, Emmanuel. Révolution personnaliste et Communautaire. Esprit, Paris, v. 32, mai 1935. Disponível em: https://esprit.presse.fr/article/esprit/la-pensee-engagee-lacollection-esprit-emmanuel-mounier-revolution-personnaliste-et-communautaire-andreulmann-quatrieme-pouvoir-police-pierre-verite-et-eugene-dabit-marche-aux-puces23488. Acesso em 28 out. 2020.

MOUNIER, Emmanuel. Che cos'è il personalismo? Torino: Einaudi, 1948.

MOUNIER, Emmanuel. Pour une démocracie personnaliste. Bulletin des Amis d'E. Mounier, Paris, n. 23-24, p. 9-13, 1964.

MOUNIER, Emmanuel. Manifesto al servizio del personalismo comunitario. Bari: Ecumenica, 1975 .

MOUNIER, Emmanuel. Cristianità nella storia. Bari: Ecumenica, 1979.

MOUNIER, Emmanuel. Rivoluzione personalista e comunitaria. Bari: Ecumenica, 1984 .

MOUNIER, Emmanuel. Il pensiero di Charles Péguy. Bari: Ecumenica, 1987.

MOUNIER, Emmanuel. Trattato del carattere. Cinisello Balsamo: San Paolo Edizioni, 1990.

MOUNIER, Emmanuel. Anarchia e personalismo. Bari: Ecumenica, 2003.

MOUNIER, Emmanuel. Il personalismo. Roma: AVE, 2014.

MOUNIER, Emmanuel. Dalla proprietà capitalista alla proprietà umana. Milano: Medusa, 2018.

PÉGUY, Charles. Véronique: dialogo della storia e dell'anima carnale. Bologna: Marietti 2013. 
WINOCK, Michel. Histoire politique de la revue Esprit. Paris: Seuil, 1975.

Recebido em: 11 jan. 2020

Aprovado em: o9 set. 2020 